\title{
AnÁlise Quantitativa da Norma CISPR 22 Versus a CISPR 25 - 30 MHz A $300 \mathrm{MHz}$
}

Kenedy Marconi G. dos Santos, Marcelo Blender Perotoni, José Osvaldo Saldanha Paulino, Mario Fernando Barbosa, Claudio Henrique G. dos Santos e Elton Jhon G. Souto

IFBA-VC - Instituto Federal da Bahia

UFABC - Universidade Federal do ABC

UFMG - Universidade Federal de Minas Gerais

USP- Universidade de São Paulo

IPT - Instituto de Pesquisas Tecnológicas

UFOP- Universidade Federal de Ouro Preto

E-mails: kenedymarconi@gmail.com, marcelo.perotoni@ufabc.edu.br, josvaldo@cpdee.ufmg.br, barbosa@ipt.br,claudiohg1@yahoo.com.br, eltonigs@gmail.com

\section{RESUMO}

Este artigo tem a finalidade de identificar as principais correlações entre as normas de compatibilidade eletromagnética criadas pelo Comité International Spécial des Perturbations Radioélectriques - CISPR, IEC CISPR 22 e IEC CISPR 25, e também definir quais são os impactos das diferenças encontradas. $O$ estudo foi realizado através de analises quantitativas na faixa de VHF - $30 \mathrm{MHz}$ a $300 \mathrm{MHz}$. Foi realizada também uma modelagem computacional com uso do software CSTMWS $\circledast$ Microwave Studio.

\section{INTRODUÇÃO}

Atualmente, com a produção em massa de tecnologias sem fio, é grande o número de sistemas eletroeletrônicos nas residências, escritórios e em veículos. No veículo, por exemplo, a eletrônica embarcada assume um papel importante nas funções de conforto, segurança e controle. A central de injeção eletrônica, o sistema de Airbag, o freio ABS, a direção elétrica, a rede de comunicação de dados e o computador de bordo são itens relevantes para a segurança e conforto. No carro elétrico, por exemplo, há um inversor de frequência que tem como objetivo principal alimentar e controlar a velocidade do motor de indução trifásico, com a utilização destes equipamentos a frequência do chaveamento vêm aumentando consideravelmente, o que leva à presença de harmônicos de frequências mais elevadas. Assim, o problema de EMC em automóveis deixou de ser apenas um requisito de garantia de qualidade do produto e tornou-se uma questão de segurança pessoal. Atualmente a segurança do veículo depende do correto funcionamento de seus sistemas eletrônicos. Em Paris por volta do ano 1934, a comunidade científica internacional se reunia para estabelecer uma metodologia de 
medição dos ruídos eletromagnéticos. O objetivo era resolver os problemas de interferências eletromagnéticas que ocorriam na recepção dos rádios. A ideia era criar um metodo científico para medir os ruídos eletromagnéticos e determinar os limites permissiveis das emissões eletromagnéticas. A esta comissão deu-se o nome de CISPR (Comité international spécial des perturbations radioélectriques).

\section{DESCRIÇÃO DO PROBLEMA}

As experiências oriundas de testes experimentais têm demonstrado que os problemas de compatibilidade eletromagnética no interior de veículos dependem principalmente da distribuição espacial dos condutores elétricos e dos componentes associados [1]. Estes últimos normalmente são instalados segundo regras que não coincidem com as da correta instalação na ótica da EMC, ou seja, em zonas em que - campo eletromagnético gerado pelos próprios componentes pode ser de tal intensidade que suas funções poderiam ser degradadas [1] e [2]. Garantir o nível de emissões eletromagnéticas dentro de limites seguros é uma meta importante para o funcionamento adequado de todos os componentes eletroeletrônicos, principalmente o sistema de recepção, presentes no veículo e no ambiente a sua volta [2]. Neste contexto, compatibilidade eletromagnética é a capacidade de um equipamento eletroeletrônico funcionar em um determinado ambiente eletromagnético sem perturbar os equipamentos adjacentes ou sem ser perturbado por outros equipamentos ou por si próprio [3]. Normalmente um problema de compatibilidade eletromagnética - EMC, como ilustra a figura 1, pode ser dividido basicamente em três partes:

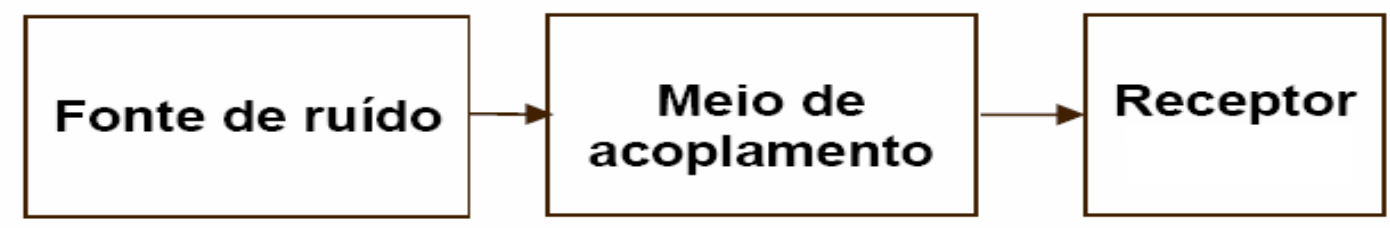

Figura 1: Diagrama em blocos referente a geração, transmissão e a vítima da interferência

Fonte de ruído - Estas fontes podem ser transmissores, motores, computadores, raios ou qualquer equipamento capaz de irradiar energia eletromagnética;

Meio de acoplamento - $\mathrm{O}$ acoplamento pode ser através de condutores, meio indutivo, capacitivo etc;

Receptor - A vítima poderá ser sistemas complexos, computadores, centrais eletrônicas etc.

A proposta deste artigo é realizar uma análise quantitativa entre as normas CISPR 22 e CISPR 25 na faixa de VHF - $30 \mathrm{MHz}$ a $300 \mathrm{MHz}$. A CISPR 25 foi criada para medir os ruídos da eletroeletrônica embarcada presente em um veículo, a 
CISPR 22 aplica-se a equipamentos de tecnologia da informação e telecomunicações. A ANATEL, para fins de certificação, estabelece requisitos de compatibilidade eletromagnética a serem atendidos pelos equipamentos de telecomunicações, tendo como referência principal a norma internacional CISPR 22.

\section{METODOLOGIA}

Após o estudo teórico das normas CISPR 22 e 25, verificou-se que havia poucas diferenças entre os arranjos físicos no laboratório na faixa de frequência de $30 \mathrm{MHz}$ a $300 \mathrm{MHz}$. As principais diferenças foram a presença de um plano de terra e os limites de average da norma CISPR 25. Para verificar qual seria a influência deste plano de massa nos resultados, foram realizadas algumas medições e simulações virtuais com e sem o plano de massa. Todas as medições foram feitas a uma distância de um metro da antena dipolo, a antena receptora utilizada no arranjo foi a antena biconicalog 3142D [11], a qual é apresentada na Figura 2. Para a execução das medições primeiramente foi escolhida uma faixa de frequência na banda de VHF que abrangessem as duas normas, ou seja, de $30 \mathrm{MHz}$ a $300 \mathrm{MHz}$. A antena receptora foi colocada em polarização vertical e horizontal para a realização das medições.

\subsection{Configuração de ensaio}

Os ensaios foram realizados em uma câmara blindada semi-anecóica [4]. Tanto para o ensaio da norma CISPR 22, quanto para o ensaio da norma CISPR 25, a antena dipolo foi colocada sobre uma mesa de material não condutivo, onde a única alteração entre os arranjos era a utilização de um plano de massa para a norma IEC CISPR 25. Na norma IEC CISPR 22 não é utilizado um plano de terra. Para fornecer energia à antena, utilizou-se um analisador de rede vetorial [5]. $O$ analisador foi colocado na parte superior da mesa, canto esquerdo, e configurado para gerar uma potência constante no valor de $20 \mathrm{dBm}$ em uma banda de frequência de $30 \mathrm{MHz}$ a $300 \mathrm{MHz}$. A antena dipolo foi ligada ao analisador de rede via um cabo coaxial e um conector BNC. Uma antena BicônicaLog 3142D foi utilizada na polarização horizontal e vertical para a medição da radiação gerada pela antena dipolo. A antena 3142D ficou posicionada a 1 metro de distância do centro da antena dipolo. Os arranjos são apresentados nas Figuras 2 e 3. 


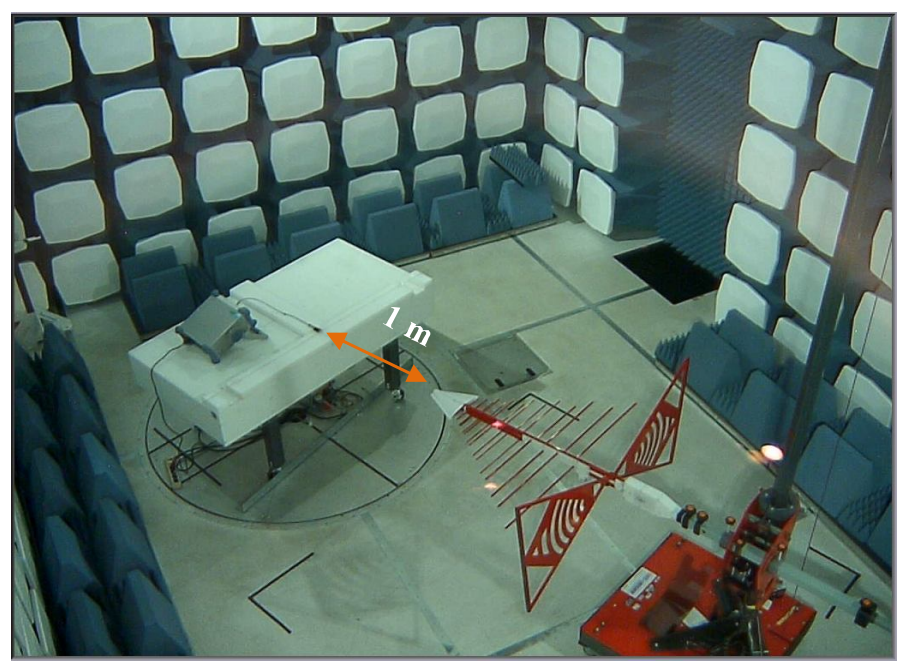

Figura 2: Arranjo utilizado para a geração do sinal de RF de $30 \mathrm{MHz}$ a $300 \mathrm{MHz}-$ IEC CISPR22

A norma CISPR 25 solicita a instalação de um plano de terra a uma altura de 900 $\mathrm{mm} \pm 50 \mathrm{~mm}$ com dimensões de $2000 \mathrm{~mm} \times 1000 \mathrm{~mm}$ aterrado ao piso. Neste ensaio a antena foi colocada em cima do plano de terra nas mesmas posições e distâncias utilizadas no arranjo da IEC CISPR 22.

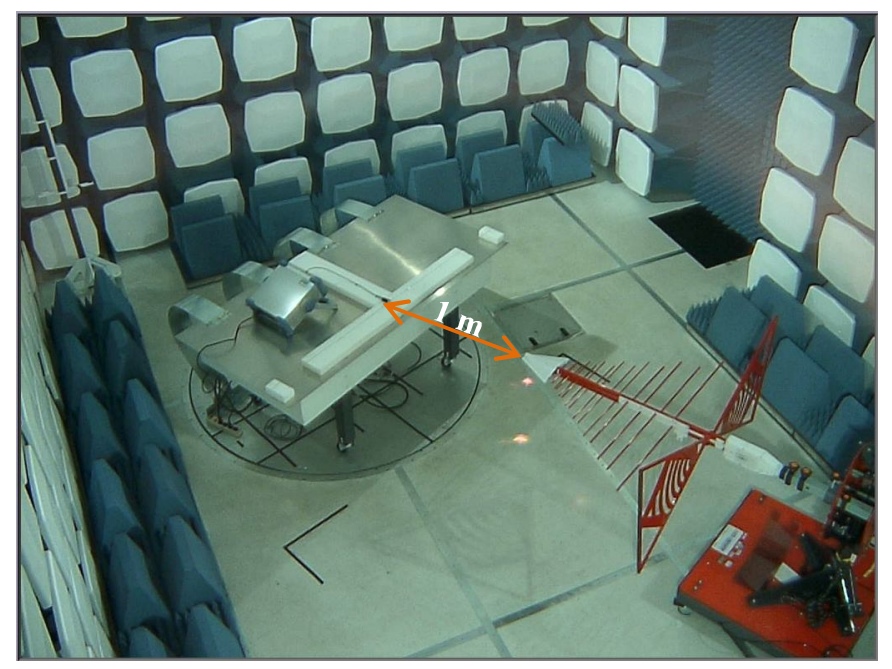

Figura 3: Arranjo utilizado para a geração do sinal de RF de $30 \mathrm{MHz}$ a $300 \mathrm{MHz}-$ IEC CISPR25

Pode-se notar que nas duas configurações, IEC CISPR 25 versus IEC CISPR22, a antena dipolo foi colocada sobre um material não condutivo, a uma altura de $5 \mathrm{~cm}$ do plano de terra e a uma distância de $15 \mathrm{~cm}$ da borda. 
De forma complementar ao ambiente de medidas em câmaras anecóicas, é possível o uso de simulações eletromagnéticas em estudos de EMC. No presente caso, um dipolo de 2,5 metros alimentado de maneira balanceada foi simulado dentro de uma câmara com piso metálico, demais paredes consideradas absorvedoras através de uma superfície PML - perfect matched layer [12] e [13]. O dipolo foi excitado e mediu-se a energia irradiada através de uma antena Log Periódica de banda larga, depois ambas foram separadas por uma distancia de 1 metro. Foram considerados dois casos, com e sem o plano de massa, da mesma forma que o ambiente de medidas. A Figura 4 ilustra o modelo computacional utilizado.

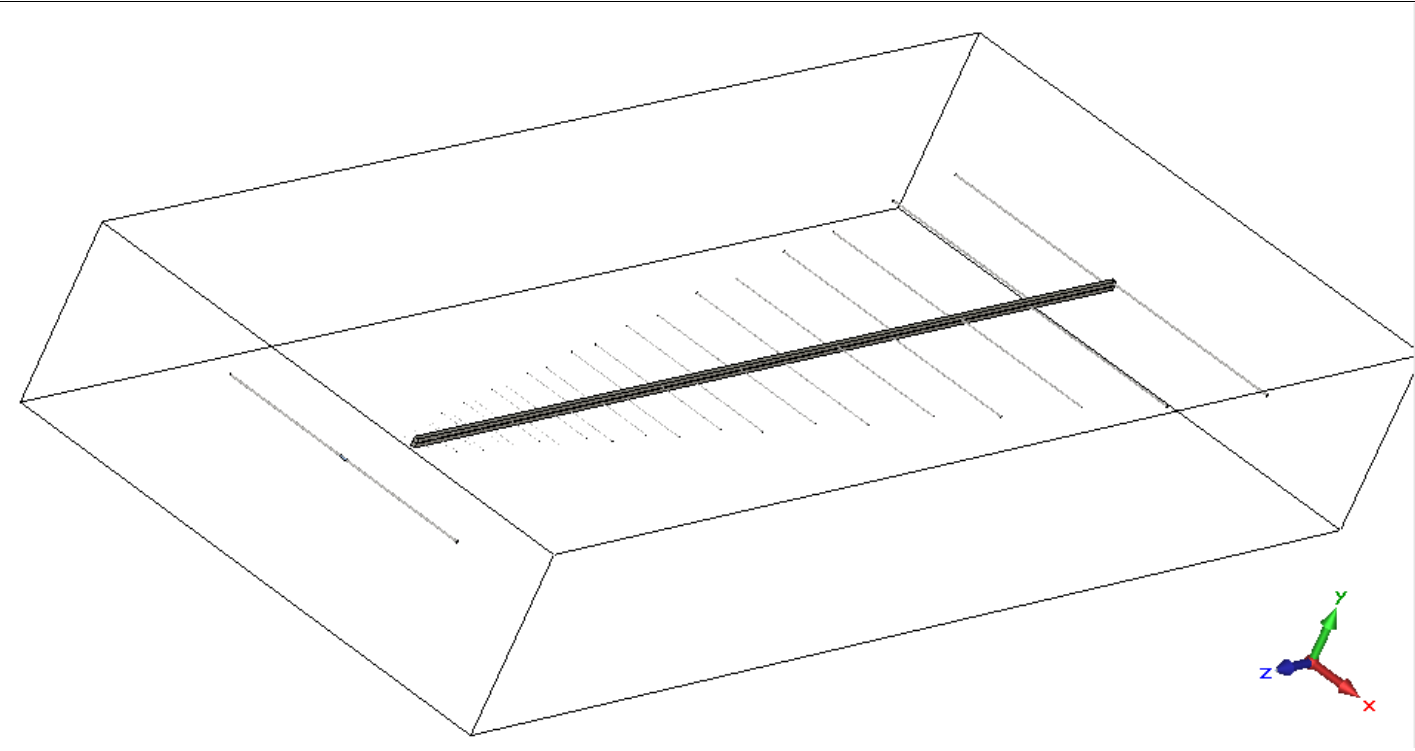

Figura 4: Modelo computacional utilizado, o qual esta fora de escala para melhor visualização.

A caixa externa simboliza a condição de fronteira do problema, modelada como um piso metálico e demais paredes como absorvedoras, emulando o efeito dos cones absorvedores. A Figura 5 abaixo mostra os parâmetros de espalhamento para a faixa de $30 \mathrm{MHz}$ a $300 \mathrm{MHz}$ da antena de 2,5 metros. Nota-se que a presença do plano de massa não exerce grande influência na perda de retorno do elemento irradiante nesta faixa de frequência. 


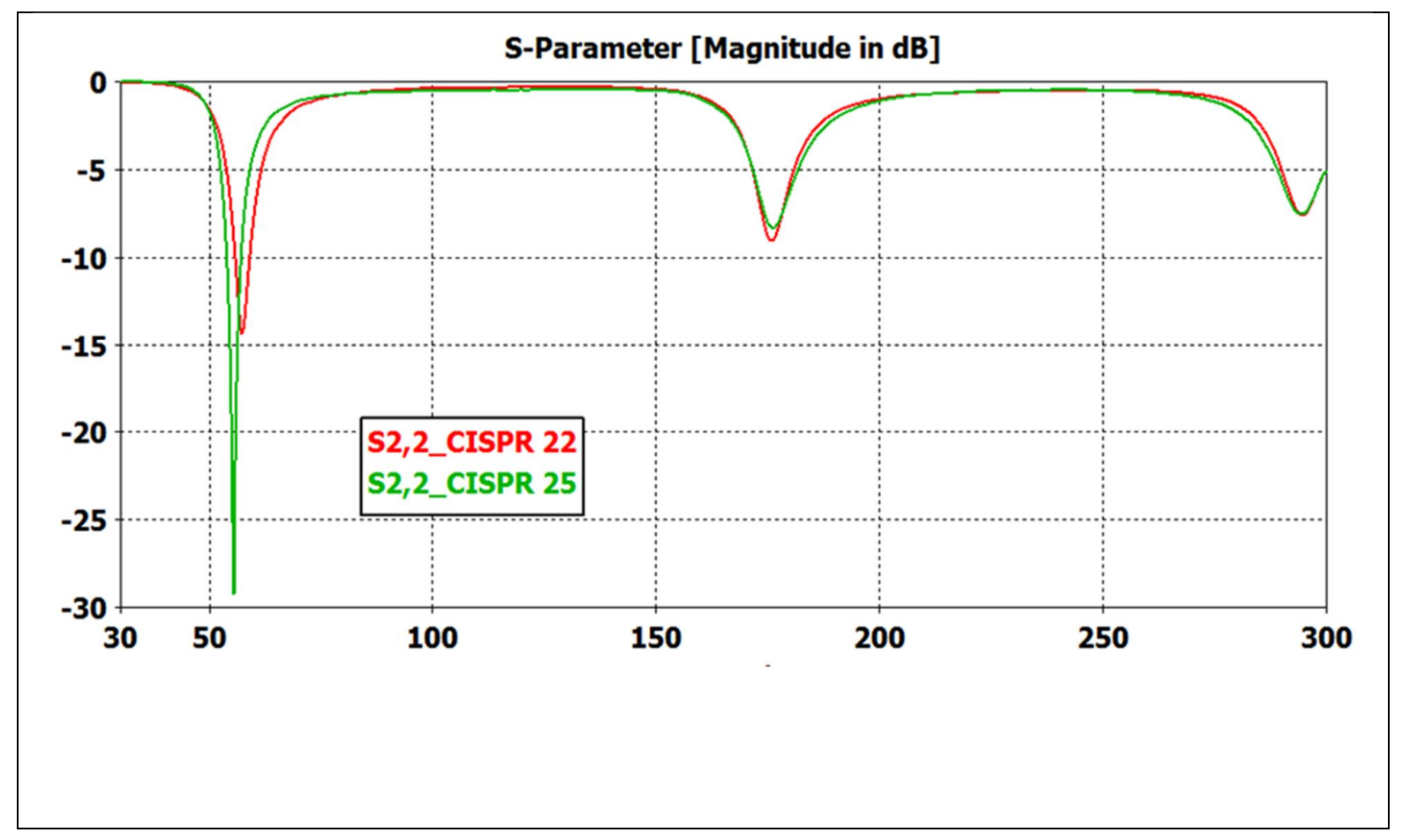

Figura 5: Perda de retorno na antena dipolo de 2.5 metros, comparando os casos com e sem planos de massa - $30 \mathrm{MHz}$ a $300 \mathrm{MHz}$.

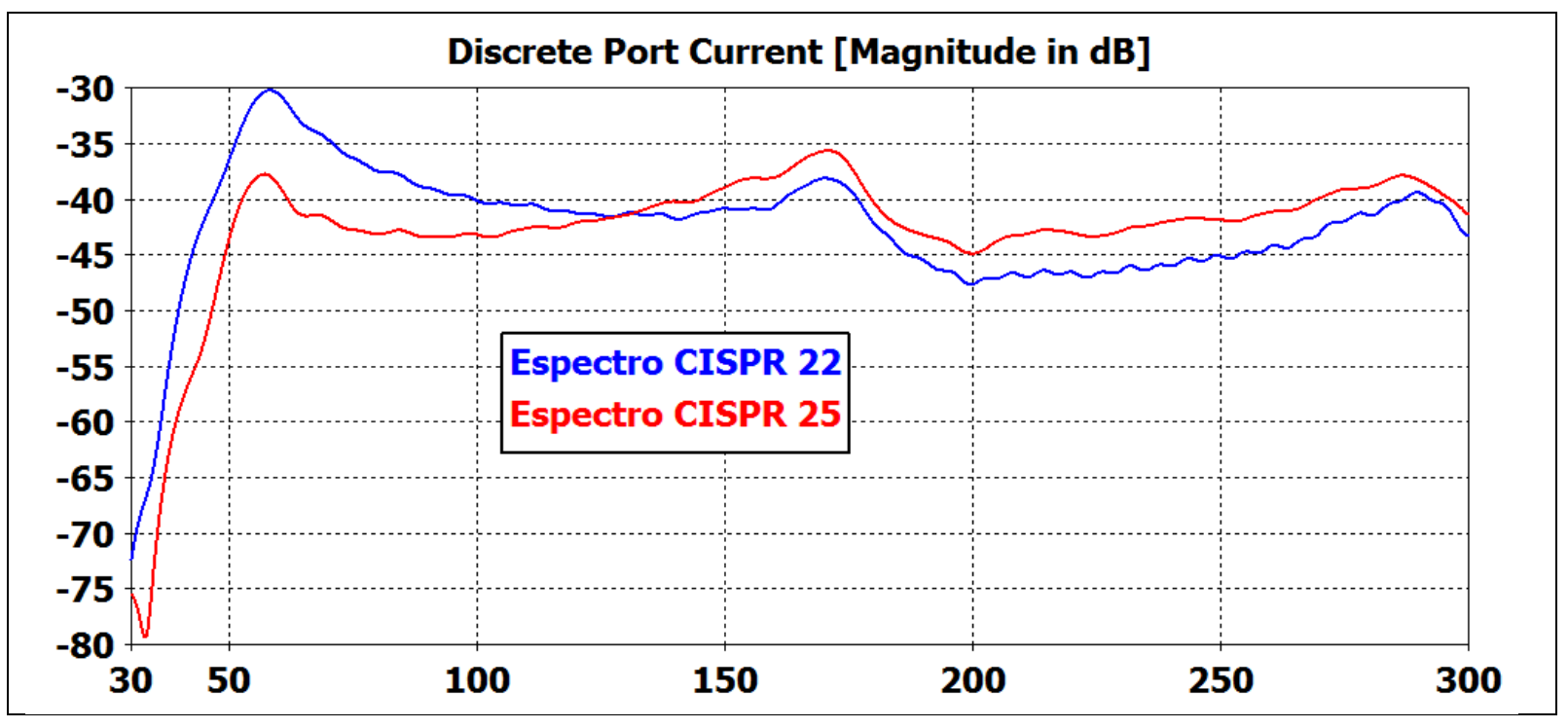

Figura 6: Amplitude com e sem plano de massa - $30 \mathrm{MHz}$ a $300 \mathrm{MHz}$.

A Figura 6 ilustra a amplitude em dB a 1 metro da antena, para os dois casos, ou seja, com e sem o plano de massa. No gráfico acima visualiza-se, que em frequências superiores a $125 \mathrm{MHz}$, a amplitude da onda eletromagnética com plano de massa é superior. Percebe-se que nos pontos próximos onde o dipolo irradia com 
maior eficiência, em torno de sua frequência de ressonância como meio comprimento de onda, a sensibilidade sem o plano de terra é mais pronunciada.

\section{Resultados:}

Os resultados apresentados aqui são frutos de dados adquiridos pelo software EMC 32 [6]. As ondas eletromagnéticas geradas pelas antenas dipolos foram medidas conforme os arranjos descritos nas normas IEC CISPR 22 e IEC CISPR 25 [7], [8] e [9]. Foram efetuadas quatro medições, duas medições para o arranjo da CISPR 22 e mais duas para a CISPR 25. Com essas medições foram feitos gráficos comparativos que são mostrados nas Figuras 7, 8, 9 e 10.

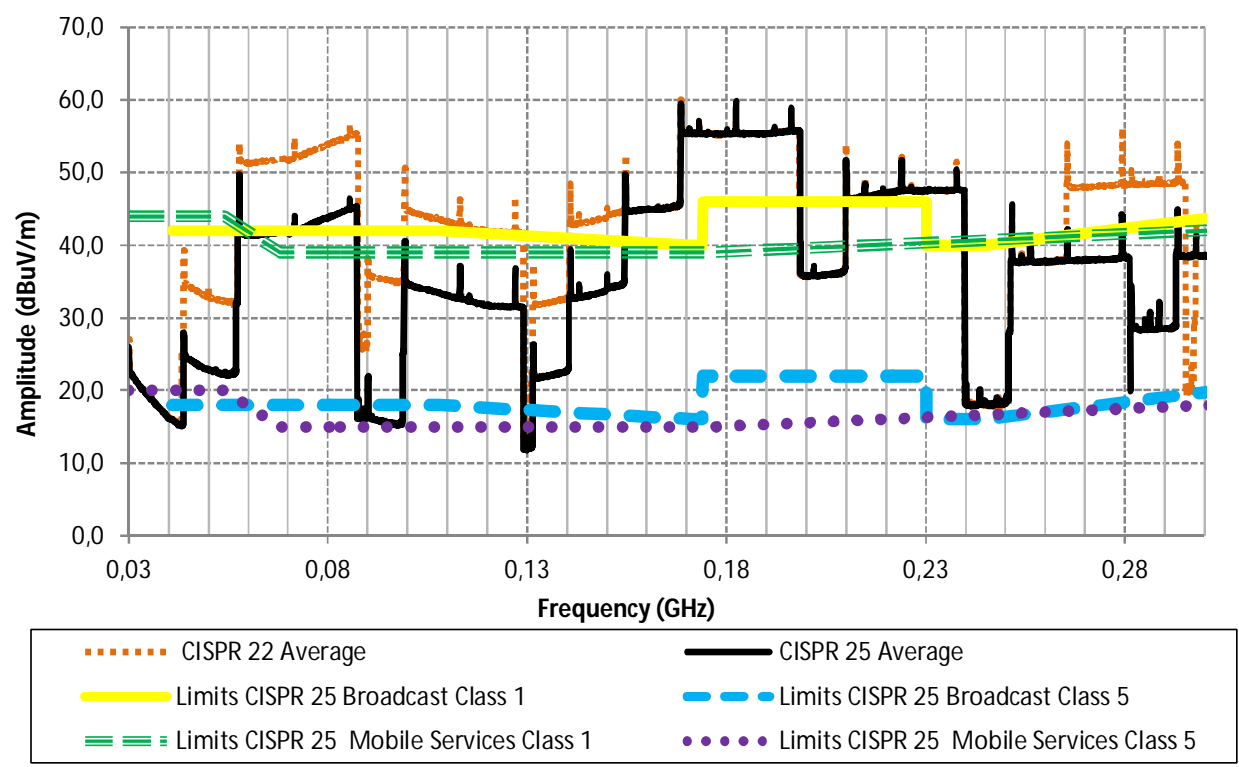

Figura 7: Dados medidos da antena dipolo de 2,5 m nos arranjos das normas CISPR 22 e CISPR 25 com polarização horizontal 


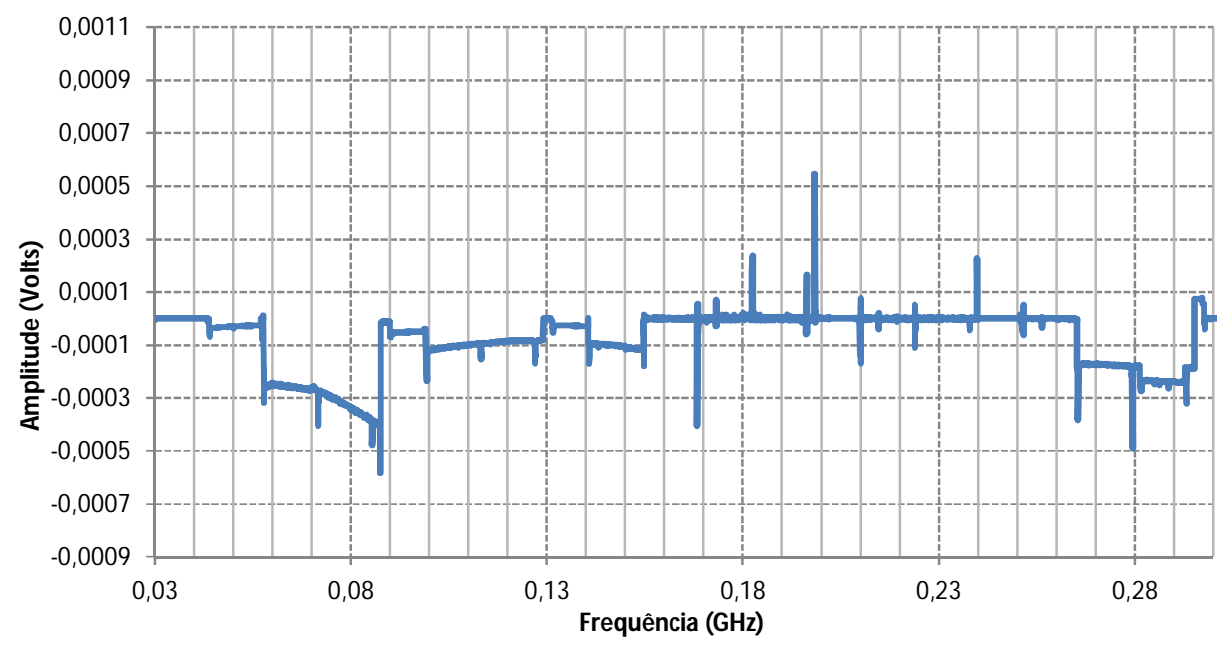

Figura 8: Diferença entre as medições da antena dipolo de $2,5 \mathrm{~m}$ com polarização horizontal

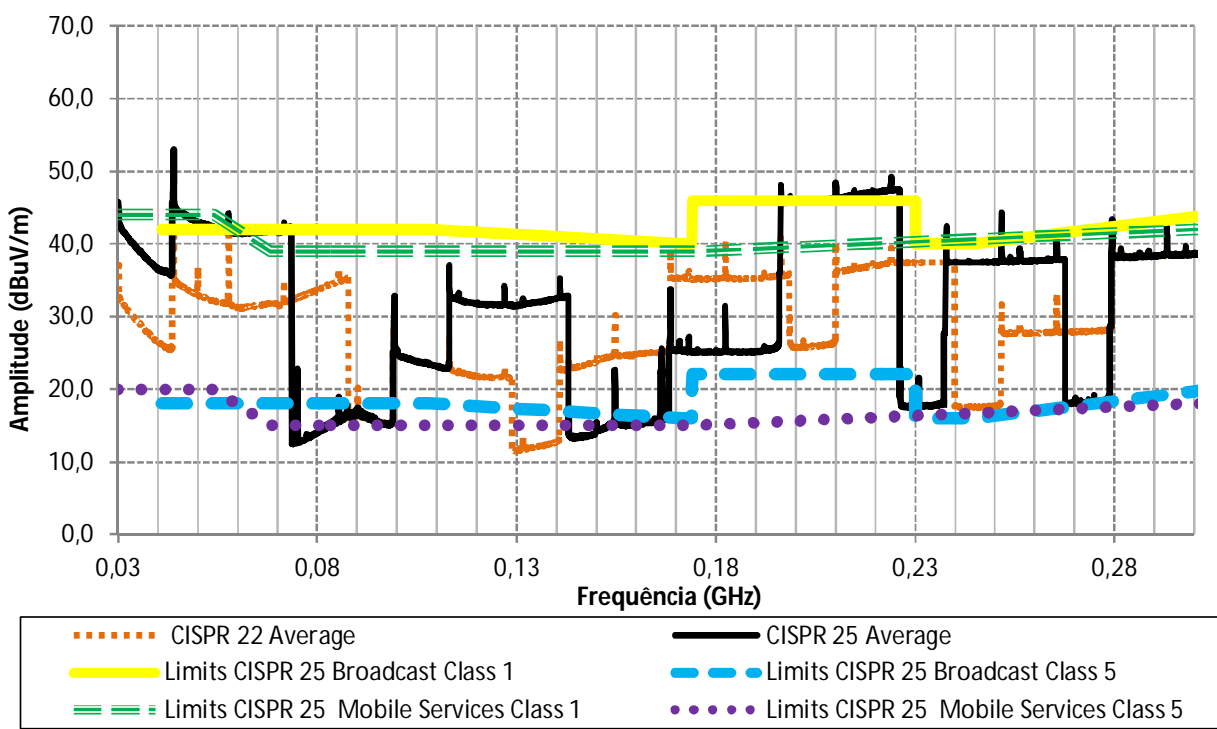

Figura 9: Dados medidos da antena dipolo de 2,5 m nos arranjos das normas CISPR 22 e CISPR 25 com polarização vertical 


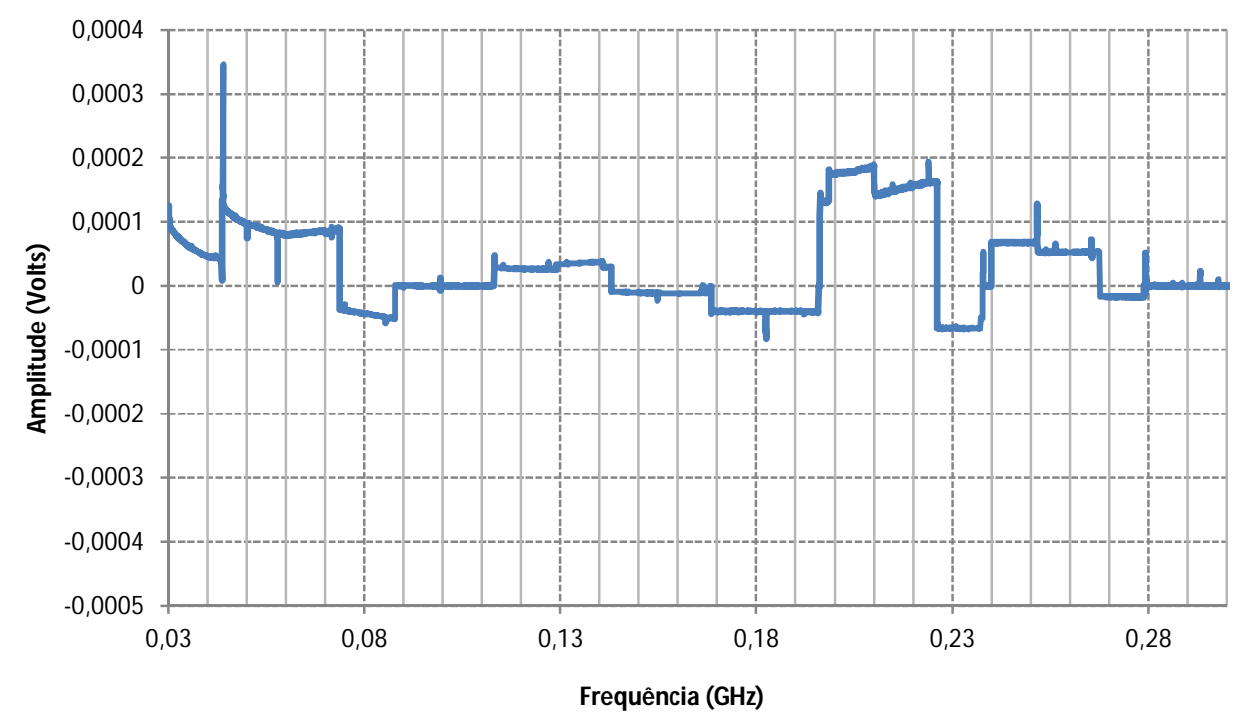

Figura 10: Diferença entre as medições da antena dipolo de 2,5 m com polarização vertical

Também é possível identificar os limites das normas CISPR 22 e CISPR 25. As Figuras 8 e 10 apresentam as diferenças entre esses dois sinais gerados pela antena dipolo, ou seja, evidenciando assim a influência do plano de massa nos arranjos.

\section{CONCLUSÃO}

Conclui-se com este trabalho que as principais diferenças entre as normas IEC CISPR 22 e IEC CISPR 25 na faixa de frequência de $30 \mathrm{MHz}$ a $300 \mathrm{MHz}$ são os arranjos e os limites. Pode-se verificar com o estudo realizado que o plano de terra existente na norma CISPR 25 é de extrema relevância tendo em vista que o piso e o "vão motor" de um veículo é uma estrutura metálica. Observou-se também, através das medições e simulações virtuais, que o plano de terra é o responsável pela elevação e a diminuição da onda eletromagnética no domínio da frequência. Tal fenômeno também é chamado de multi-percurso ou multipath. Analisando somente a reflexão do plano de terra, na condição ideal que é a reflexão máxima, ondas em fase, teremos o dobro do valor de campo elétrico medido sem o plano de massa (IEC CISPR 22). Na interferência destrutiva, com as ondas defasadas de cento e oitenta graus, o campo será cancelado quando comparado com o arranjo da IEC CISPR 22. O próximo objetivo dos autores será realizar o mesmo estudo proposto nesse artigo na faixa de $300 \mathrm{MHZ}$ a $2.5 \mathrm{GHz}$. 


\section{REFERÊNCIAS}

[1] SANTOS, L. A. L., Análise Experimental do Ensaio Veicular de Imunidade a Campos Eletromagnéticos Radiados em Câmara Semi-anecóica de Pequeno Porte. Dissertação de Mestrado, Universidade Federal de Minas Gerais. Belo Horizonte: UFMG, 2007;

[2] SANTOS, K. M. G. dos, Medição do Fator de Blindagem de Cabos Coaxiais. Dissertação de Mestrado, Universidade Federal de Minas Gerais, Belo Horizonte:

UFMG, 2011;

[3] PAUL, C.R, Introduction to Electromagnetic Compatibility, John Wiley \& Sons, Inc., New York, New York, 1992.

[4] IPT- Instituto de Pesquisas Tecnológicas; Disponível na Internet em <http://www.ipt.br/ipt_na_midia/102-compatibilidade_eletromagnetica.htm> Acessado em 06/05/2013;

[5] R\&S- Rohde\&Schwarz; Disponível na Internet em <http://www.rohdeschwarz.com.br/pt/products/testemedida/network_analysis/ZVL6.html>Acessado em 06/05/2013;

[6] EMC32, EMC measurement software. Disponível na Internet em <http://www2.rohde-schwarz.com/product/EMC32.html>. Acessado em 06/05/2013;

[7] INTERNATIONAL ELECTROTECHNICAL COMMISSION, International Special Committee on Radio Interference Document (CISPR 25), International Electrotechnical Commission Central Office, 2008;

[8] INTERNATIONAL ELECTROTECHNICAL COMMISSION, International Special Committee on Radio Interference Document (CISPR 22), International Electrotechnical Commission Central Office, 2008;

[9] CISPR 16-1: Radio Disturbance and Immunity Measuring Apparatus,1993, p.15-73.

[10] KRAUS, John D., Antenas, Guanabara Dois, Rio de Janeiro, 1983, p. 01-07, 419-455.

[11] Antena ETS - 3142, Disponível na Internet em <http://www.etslindgren.com/search\&search=3142D>Acessado em 08/05/2013;

[12] SADIKU,Matthew N.O., Numerical Techniques in Electromagnetics, CRC Press, Boca Raton FL, 2001.

[13] CST Microwave Studio cst Computer Simulation,Technology; AG. Disponível na Internet em <http://www.cst.com/Content/Applications/Markets/EMC EMI.aspx> Acessado em 02/05/2013; 